University of South Carolina

Scholar Commons

$8-2000$

\title{
AINTEGUMENTA Promotes Petal Identity and Acts as a Negative Regulator of AGAMOUS
}

\author{
Beth A. Krizek \\ University of South Carolina - Columbia, krizek@sc.edu \\ Valerie Prost \\ University of South Carolina - Columbia \\ Anthony Macias
}

Follow this and additional works at: https://scholarcommons.sc.edu/biol_facpub

Part of the Biology Commons

\section{Publication Info \\ Published in The Plant Cell, Volume 12, Issue 8, 2000, pages 1357-1366. \\ (C) The Plant Cell 2000, American Society of Plant Physiologists.}

This Article is brought to you by the Biological Sciences, Department of at Scholar Commons. It has been accepted for inclusion in Faculty Publications by an authorized administrator of Scholar Commons. For more information, please contact digres@mailbox.sc.edu. 


\title{
AINTEGUMENTA Promotes Petal Identity and Acts as a Negative Regulator of AGAMOUS
}

\author{
Beth A. Krizek, ${ }^{1}$ Valerie Prost, and Anthony Macias \\ Department of Biological Sciences, University of South Carolina, Columbia, South Carolina 29208
}

\begin{abstract}
The Arabidopsis AINTEGUMENTA (ANT) gene has been shown previously to be involved in ovule development and in the initiation and growth of floral organs. Here, we show that ANT acts in additional processes during flower development, including repression of AGAMOUS (AG) in second whorl cells, promotion of petal epidermal cell identity, and gynoecium development. Analyses of ap2-1 ant-6 double mutants reveal that ANT acts redundantly with AP2 to repress AG in second whorl cells. The abaxial surface of ant petals contains features such as stomata and elongated, interdigitated cells that are not present on wild-type petals. The loss of petal identity in these second whorl cells does not result from ectopic AG expression, suggesting that ANT acts in a pathway promoting petal cell identity that is independent of its role in repression of AG. These data suggest that ANT may function as a class $A$ gene.
\end{abstract}

\section{INTRODUCTION}

Organ identity in flowers is specified by homeotic genes with activities in different regions of a developing flower. Three classes of floral homeotic genes are proposed to function in overlapping domains to specify the identity of sepals in whorl one, petals in whorl two, stamens in whorl three, and carpels in whorl four (Bowman et al., 1991; Coen and Meyerowitz, 1991; Meyerowitz et al., 1991). In Arabidopsis, the A class genes APETALA1 (AP1) and APETALA2 (AP2) act to specify sepal and petal development, the $B$ class genes APETALA3 (AP3) and PISTILLATA (PI) act to specify petal and stamen development, and the class $C$ gene AGAMOUS (AG) acts to specify stamen and carpel development. In many cases, these gene activities are restricted to particular regions by means of transcriptional regulation. Several genes controlling the establishment or maintenance of such region-specific expression have been described. The floral meristem identity gene LEAFY (LFY) is expressed throughout young floral meristems and appears to act with different region-specific factors to activate the expression of AP3 and AG in particular floral whorls (Parcy et al., 1998; Busch et al., 1999).

The spatial restriction of AG to third and fourth whorls is controlled by several partially redundant factors, including AP2, LEUNIG (LUG), CURLY LEAF (CLF), and STERILE APETALA (SAP). Mutations in these genes result in various amounts of $A G$ misexpression in different regions of the plant. The major repressor of $A G$ in first and second whorl ${ }^{1}$ To whom correspondence should be addressed. E-mail krizek@
sc.edu; fax 803-777-4002. cells is AP2. Loss of AP2 function results in ectopic AG expression in the outer two whorls and the corresponding homeotic transformations of these organs to carpels and stamens, respectively (Drews et al., 1991). lug mutants show similar but weaker homeotic transformation in the outer two whorls and have been isolated as enhancers of the weak ap2-1 allele (Liu and Meyerowitz, 1995). In addition to the spatial expansion of the AG expression domain in both ap2 and lug mutants, AG expression is initiated slightly earlier in both of these mutants. A third gene that acts to repress $A G$ in whorls one and two is SAP. Early sap flowers produce sepals and small petals, whereas later flowers produce carpelloid sepals and lack second whorl organs (Byzova et al., 1999). AG misexpression is observed in all floral whorls and in the inflorescence meristem of sap mutants. CLF acts primarily to negatively regulate $A G$ expression in vegetative tissues and to maintain repression of $A G$ in flowers at older developmental stages (Goodrich et al., 1997). The predominant phenotype of clf mutants is the curling of leaf margins toward the midrib because of ectopic AG expression in leaves.

Another gene that has been speculated to play a cadastral role in restricting $A G$ expression to third and fourth whorl cells is ANT (Elliott et al., 1996). Mutations in ANT cause a decrease in floral organ number and alterations in the appearance of all floral organs (Figures $1 \mathrm{~A}$ and $1 \mathrm{~B}$ ) (Elliott et al., 1996; Klucher et al., 1996; Baker et al., 1997; Sanders et al., 1999). In addition, ant ovules are blocked in integument initiation and megasporogenesis (Elliott et al., 1996; Klucher et al., 1996; Baker et al., 1997; Schneitz et al., 1997). Although ant mutants show no homeotic transformation of organ identity, ap2-2 ant-9 double mutants show a severe 
phenotype that resembles ap2-9 lug-1 double mutants (Elliott et al., 1996). Flowers of these double mutants consist of a central carpel (often unfused) and an outer filament or thin bractlike structure. Both ap2 and ant single mutants contain fewer floral organs than wild type. Whereas ANT is thought to function as a growth-promoting gene, the decreased number of floral organs in ap 2 mutants results from the growth suppression effects of ectopic $A G$ expression in first and second whorl cells (Bowman et al., 1991). Two possible interpretations of the ap2-2 ant- 9 double mutant phenotype have been suggested (Elliott et al., 1996). AP2 and ANT may have partially redundant functions in promoting organ initiation, or AP 2 and ANT may have partially redundant functions in repression of $A G$. In the latter case, the severe reduction in organ number would result from increased $A G$ misexpression and its associated growth suppression. Possible redundancy between ANT and AP2 is supported at the molecular level because ANT encodes a member of the AP 2 family of transcription factors (Elliott et al., 1996; Klucher et al., 1996).

To further investigate whether ANT acts redundantly with AP2 to repress AG, we have made double mutants with the weak ap2-1 allele as well as other genes that act as repressors of AG expression. Enhancement of the ap2-1 phenotype by ant- 6 as well as increased misexpression of AG in ap2-1 ant- 6 second whorl organs indicate that ANT does act as a redundant repressor of AG. In addition, ANT appears to be a positive regulator of specification of petal cell type because ant- 6 petals exhibit a slight loss in petal identity that is not attributable to ectopic AG. The roles of ANT in repression of $A G$ and promotion of petal identity reveal that ANT may function as a second whorl class $A$ gene.

\section{RESULTS}

\section{ant Second Whorl Organs Show Partial Loss of Petal Identity}

Epidermal cells on sepals, petals, stamens, and carpels show characteristic surface morphologies. Cells on the abaxial surface of sepals are of different sizes, with some quite elongated cells, some smaller cells, and stomata (Figure 2A). Cells on both the adaxial and abaxial surfaces of wild-type petals are round in appearance. Those on the adaxial surface are more cone-shaped, with cuticular thickenings running down the sides of the cone (Figure 2B), whereas those on the abaxial surface are flatter and more cobblestone-like (Figure 2C). Stomata are not present on either surface of petals. Anther epidermal cells are more irregular in shape than those of petals and are interdigitated (Figures 2D and 2E). Stomata are present on the abaxial anther surface (Figure 2E). Cells on the adaxial surface of ant- 6 petals have a morphology similar to those of wild-type petals (Figure 2F). The abaxial surface of ant- 6 petals, however, contains stomata and irregularly shaped cells (Figures 2G and $2 \mathrm{H}$ ). These cells somewhat resemble epidermal cells of anthers as well as cells found on the abaxial surface of clf- 2 second whorl organs. The longer epidermal cells and stomata of ant -6 petals tend to be present in the middle of the organ, whereas cells on the margins tend to resemble those found on wild-type petals. This petal phenotype is found on ant alleles of various strengths (ant- 4 , ant- 6 , and ant-8). The altered morphology of these cells reflects a loss of petal identity and perhaps a change to anther identity.

\section{AG Expression Is Not Detected in ant Petals}

To determine whether ectopic AG expression might be responsible for the ant second whorl abaxial epidermal cell phenotype, in situ hybridization was performed on wild-type (Landsberg erecta [Ler]) and ant inflorescence tissue using an $A G$ antisense probe. Similar patterns of $A G$ expression were found in Ler, ant-4, and ant- 6 flowers, the AG mRNA being confined to third and fourth whorl organs (Figures $3 B$ and $3 C$ ). No AG expression was observed in the first or second whorls of ant flowers (Figure $3 \mathrm{C}$ ). In addition, the temporal pattern of AG expression was unchanged in ant mutants. To confirm that the in situ experiments were able to detect low amounts of AG expression, clf- 2 tissue was hybridized alongside ant tissue in these experiments. Patches of $A G$ expression were detected in the second whorl petals of clf-2 mutants (Figure 3D).

The possible involvement of AG in the ant petal phenotype was also investigated by making ag- 3 ant- 6 double mutants. ag- 3 plants produce indeterminate flowers consisting of the repeating pattern sepals, petals, petals (Bowman et al., 1991). The double mutant flowers consist of repeating whorls of sepals, petals, petals, but the petals resemble those found in ant- 6 with regard to organ size (Figure $1 C$ ) and cell morphology (Figures $4 \mathrm{~A}$ to $4 \mathrm{C}$ ). Stomata and irregularly shaped cells were detected on the abaxial surface of ag-3 ant- 6 petals (Figures 4B and 4C). The appearance of abaxial epidermal cells of ag- 3 ant- 6 varied somewhat; in some cases, the cells looked rather normal, but stomata were still present (Figure $4 \mathrm{C}$ ). The in situ experiments and the phenotype of ag- 3 ant- 6 flowers indicate that the ant petal phenotype is not due to AG.

\section{ant-6 Enhances the Second Whorl Phenotype of ap2-1 Mutants}

The weak ap2-1 allele produces flowers with leaflike organs in whorl one, slightly staminoid petals in whorl two, stamens in whorl three, and carpels in whorl four (Figure 1D; Bowman et al., 1989). ap2-1 ant- 6 flowers produce leaflike organs in whorl one, staminoid organs in whorl two, stamens in whorl three, and carpels in whorl four (Figure $1 E)$. Thus, ap2-1 is epistatic to ant- 6 with regard to organ 
A

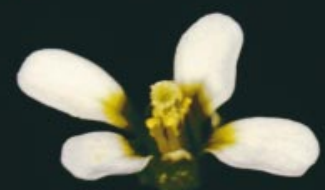

Ler

D

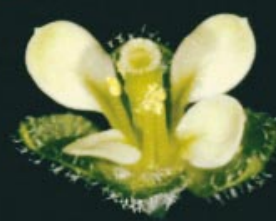

ap2- 1
B

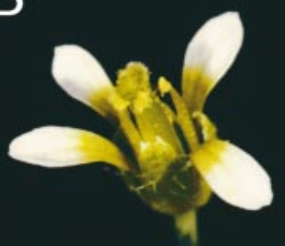

ant- 6

$\mathrm{E}$

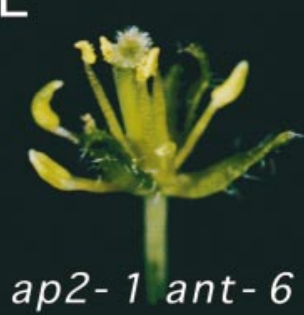

C
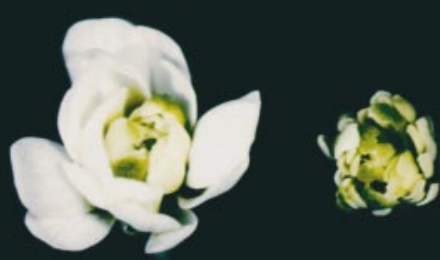

ag- 3 ag- 3 ant- 6

F

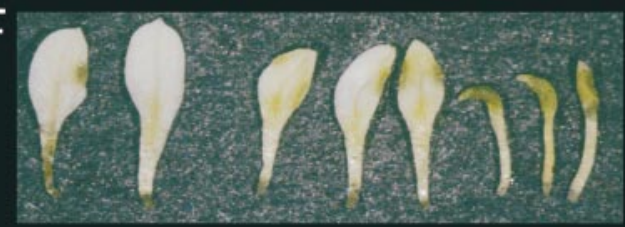

$$
\begin{array}{lll}
\text { ap2-1 } & \text { ap2-1 } & \text { ap2-1 } \\
& \text { ant-6/+ } & \text { ant-6 }
\end{array}
$$

$\mathrm{H}$

G
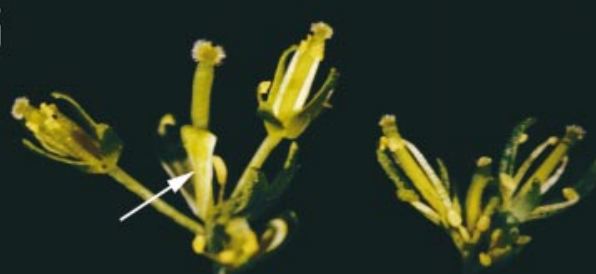

$$
\text { ap1-1 ap1-1 ant-6 }
$$

I

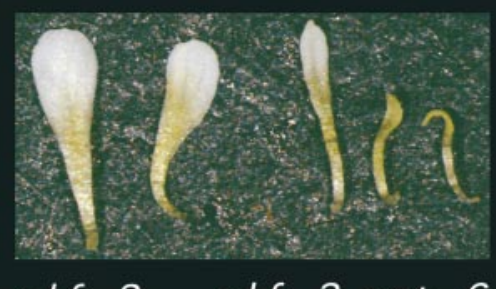

$\mathrm{J}$

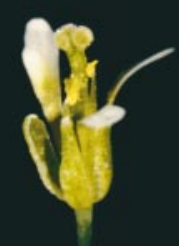

lug- 1

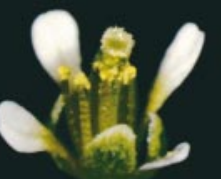

clf -2

clf- 2 ant- 6

$\mathrm{K}$

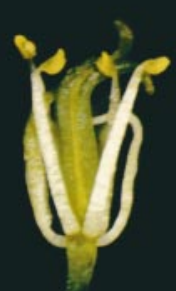

L

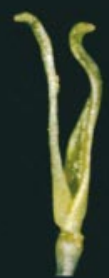

Iug- 1 ant-6 Iug- 1 ant- 6

Figure 1. Ler, ant- 6 , and ant- 6 Double Mutants.
(A) Ler.
(B) ant-6.
(C) ag-3 and ag-3 ant-6.
(D) ap2-1.
(E) ap2-1 ant-6.
(F) Second whorl organs from ap2-1, ap2-1 ant-6/+, and ap2-1 ant-6.
(G) ap 1-1 and ap1-1 ant-6. Arrow indicates a petaloid organ in ap1-1.
(H) clf- 2 and clf- 2 ant- 6 .
(I) Second whorl organs from clf-2 and clf-2 ant-6.
(J) lug-1.
(K) lug-1 ant-6.
(L) lug-1 ant-6 fourth whorl. 

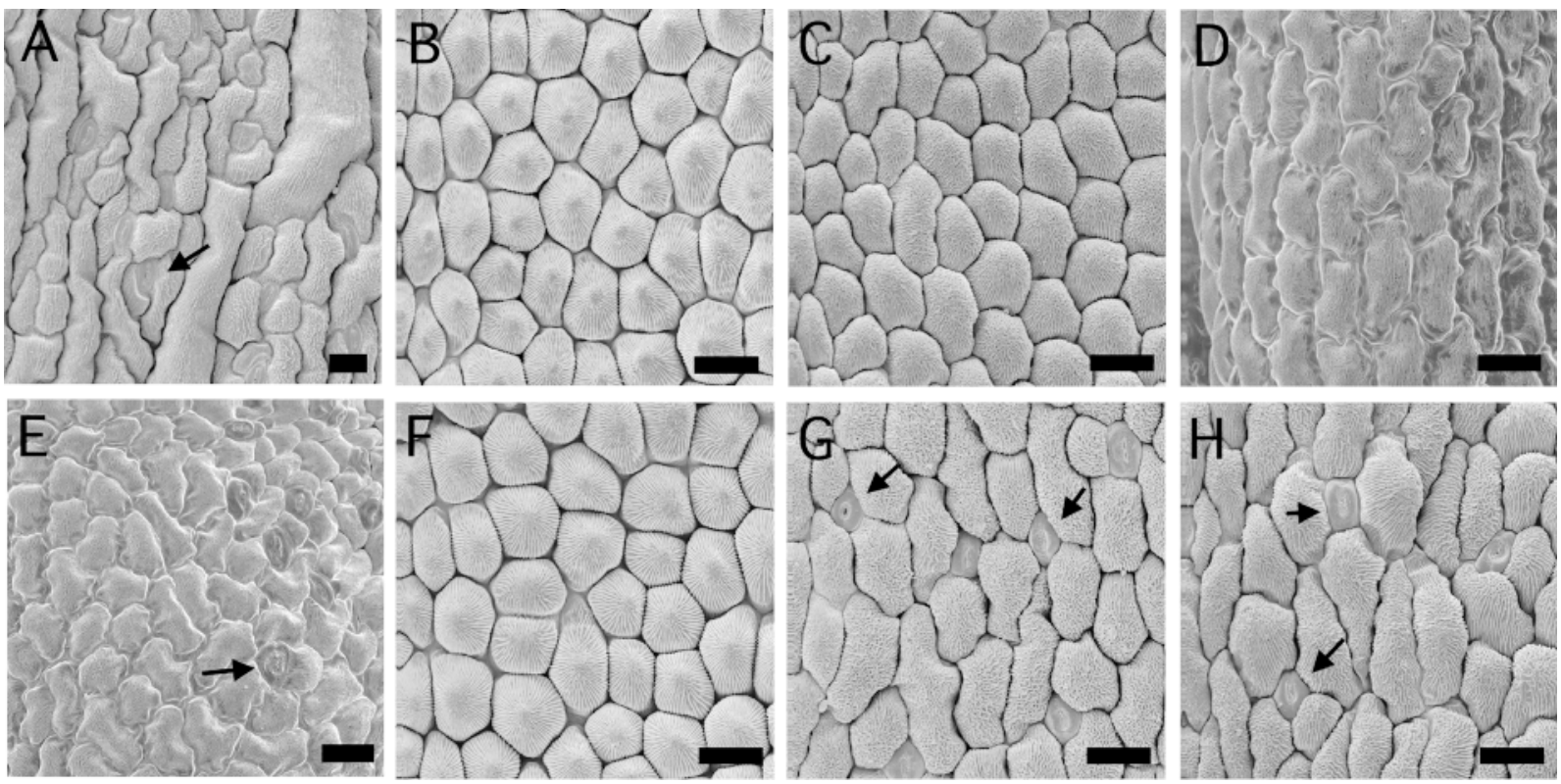

Figure 2. Scanning Electron Micrographs of Ler and ant-6 Floral Organs.

(A), (C), and (E) Abaxial epidermis of sepal (A), petal (C), and anther (E) from Ler.

(B) and (D) Adaxial epidermis of petal (B) and anther (D) from Ler.

(F) Adaxial epidermis of an ant- 6 petal.

(G) and (H) Abaxial epidermis of an ant- 6 petal.

Arrows indicate stomata. Bars $=10 \mu \mathrm{m}$.

identity in whorl one. Organs in whorls one, three, and four resemble ant- 6 organs in their morphology; they tend to be narrow, and the stamens consist of two locules rather than four. In addition, organ number is decreased in the double mutant. An average of 3.5, 2.9, 4.1, and 2.0 floral organs are found in whorls one to four of the double mutant, compared with an average of $4.0,3.3,5.4$, and 2.0 organs in the respective whorls of ap2-1.

Second whorl organs in the double mutant show an enhanced transformation to staminoid organs (Figure $1 F$ ). The earliest-formed second whorl organs were leaflike, petallike, or stamenlike in overall appearance (Figures 5B, 5] , and $5 \mathrm{~K}$ ) with cell types characteristic of all of these organs present on the adaxial surface (Figure 5F). The abaxial surface tended to be more leaflike, with some cells lacking epicuticular thickenings (Figure 50), and trichomes occasionally were present. Often, the abaxial surface of these organs had cell types similar to those found on the abaxial surface of ap 2-1 organs (Figures $5 \mathrm{M}$ and $5 \mathrm{~N}$ ). In later-arising ap2-1 ant- 6 flowers, the second whorl organs were more staminoid in overall appearance (Figures 5C, 5D, and 5L). These second whorl organs often possessed loculelike structures (Figure 5D) with cell types characteristic of anthers (Figure $5 \mathrm{H}$ ). The abaxial surface of these organs often remained leaflike but sometimes had cells that were more staminoid in shape than those on ap2-1 organs (Figure 5P). The transformation to stamen identity was not total: only some of these second whorl organs produced pollen.

Flowers of plants with the genotype ap2-1 ant-6/+ showed a slightly more severe phenotype than ap2-1 flowers. The second whorl organs tended to be somewhat smaller, more pointed, and more yellow in color (Figure $1 F$ ). Thus, ant- 6 becomes partially dominant in an ap2- 1 background. No phenotypic differences were observed between ap2-1/+ ant- 6 flowers and those of ant- 6 .

\section{Enhancement of ap2-1 Phenotype Correlates with Increased AG Expression}

The presence of AG RNA in first and second whorl organs of ap2-1 flowers has been described previously (Drews et al., 1991). In those experiments, low amounts of AG RNA were detected in ap2-1 first whorl cells, and patches of AG RNA were detected in some ap2-1 second whorl organs. To determine whether the increased stamen identity of ap2-1 ant- 6 second whorl organs is the result of increased amounts of AG ectopic expression in these organs, the pattern of $A G$ expression was examined in ap2-1 and ap2-1 ant- 6 flowers. AG expression was first observed in stage 3 flowers of ap2-1 
(Figure 3E) and ap2-1 ant-6 (Figure 3I) in cells of the floral meristem but not in the young first whorl primordia, similar to the pattern observed in wild-type flowers (Figure 3A). At later stages in flower development, AG RNA was detected in patches of adaxial epidermal cells (Figures $3 \mathrm{~F}$ and $3 \mathrm{H}$ ) and occasionally in some subepidermal layers on the adaxial side of second whorl organs. The pattern of $A G$ expression in ap2-1 ant-6 second whorl organs was somewhat expanded. Patches of AG RNA were detected more frequently in subepidermal tissue of the double mutant (Figures $3 \mathrm{~J}$ to
$3 \mathrm{~L})$. Expression was sometimes seen on the abaxial side of ap2- 1 ant- 6 second whorl organs. In addition, the frequency of AG expression in ap2-1 ant- 6 second whorl organs was greater than in ap2-1. In flowers of stages 6 through 10, AG expression was observed in 18 of 19 second whorl organs from ap2-1 ant- 6 and in 9 of 17 second whorl organs from ap2-1. The enhanced staminoid appearance of the adaxial surface of ap2-1 ant- 6 second whorl organs in comparison with the abaxial surface is consistent with the increased presence of AG ectopic expression in these regions of second whorl organs.

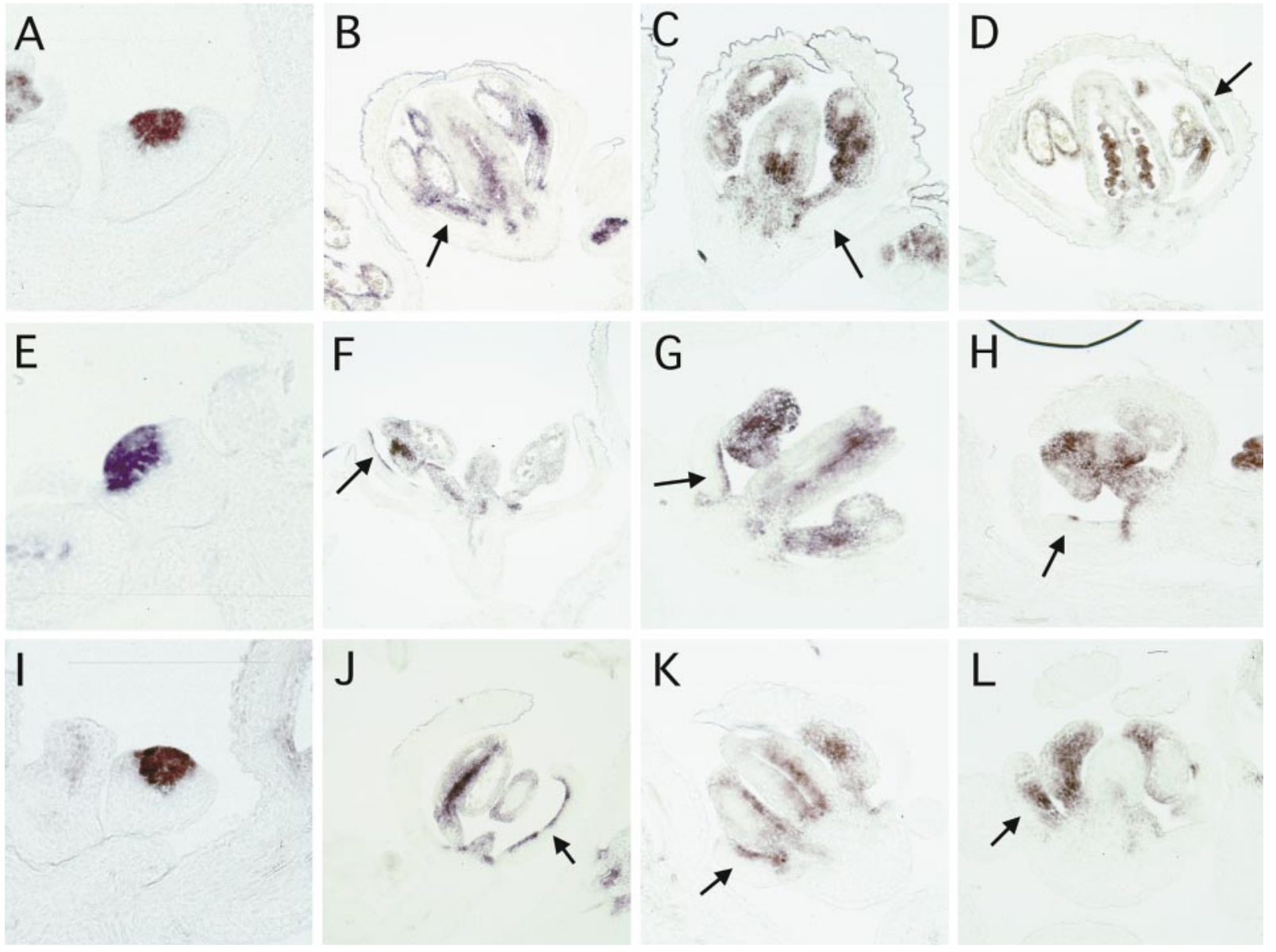

Figure 3. Localization of AG RNA in Longitudinal Sections of Flowers from Ler, ant-4, clf-2, ap2-1, and ap2-1 ant- 6 by in Situ Hybridization. Arrows indicate second whorl organs that either show no AG expression ([B] and [C]) or that do exhibit ectopic AG expression ([D], [F], [G], [H], [J ], [K], [L]).

(A) Stage 3 wild-type (Ler) flower.

(B) Stage 10 wild-type (Ler) flower.

(C) Stage 9 ant-4 flower.

(D) Stage 12 clf-2 flower.

(E) Stage 3 ap2-1 flower.

(F) to (H) ap2-1 flowers at stages 8 to 13. AG RNA is detected in patches of epidermal cells of second whorl organs.

(I) Stage 3 ap2-1 ant-6 flower.

( ) to (L) ap2-1 ant-6 flowers at stages 8 to 12 . AG RNA is detected in epidermal and some subepidermal cells of ap2-1 ant- 6 second whorl organs. 

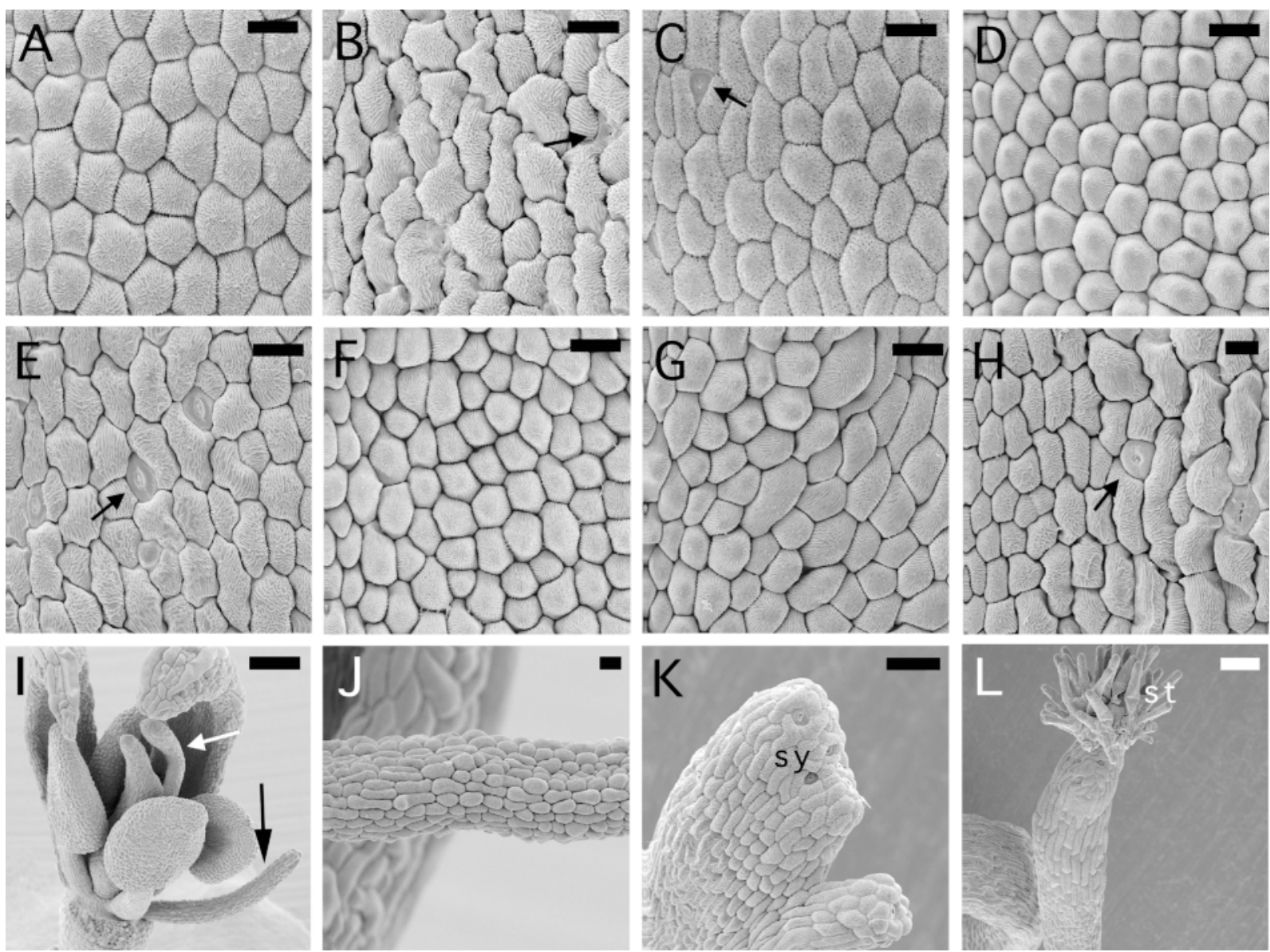

Figure 4. Scanning Electron Micrographs of ag-3, ag-3 ant-6, clf-2, clf- 2 ant- 6 , and lug- 1 ant- 6 Flowers.

(A) Abaxial epidermis of an ag-3 petal.

(B) and (C) Abaxial epidermis of an ag-3 ant-6 petal. Stomata and elongated, interdigitated cells are present on these second whorl organs.

(D) and (E) Adaxial (D) and abaxial (E) epidermis of a clf-2 petal.

(F) Adaxial epidermis of a clf- 2 ant- 6 second whorl organ.

(G) Adaxial epidermis of a clf-2 ant- 6 second whorl organ with some cone-shaped cells as well as some flattened cells.

(H) Abaxial epidermis of a clf- 2 ant- 6 petal.

(I) lug-1 ant- 6 flower with a filament in the second whorl (black arrow) and an unfused gynoecium (white arrow).

(J) Petaloid filament found in the second whorl of a lug- 1 ant- 6 flower.

(K) Apical region of a lug-1 ant- 6 gynoecia with horn-like protrusions consisting of stylelike tissue (sy).

(L) Hornlike protrusion of a lug-1 ant- 6 gynoecium topped with stigmatic papillae (st).

Arrows in (B), (C), (E), and (H) indicate stomata. Bars in (A) to (H) and $\mathbf{( J )}=10 \mu \mathrm{m}$; bars in (I) and $(\mathbf{L})=50 \mu \mathrm{m}$; bar in $(\mathbf{K})=30 \mu \mathrm{m}$.

\section{Decreased Petal Identity in ap1-1 ant-6 and clf-2 ant-6 Double Mutants}

ap1-1 flowers contain leaflike organs in whorl one, stamens in whorl three, and carpels in whorl four and are usually missing second whorl organs. In addition to these defects in floral organ identity, ap 1-1 flowers produce additional flowers in the axils of the first whorl organs (Figure 1G) (Irish and
Sussex, 1990; Bowman et al., 1993). ap1-1 ant-6 double mutants resemble ap1-1 with regard to floral organ identity and resemble ant- 6 with respect to floral organ and ovule morphology (Figure 1G). Although petals and petaloid organs are rarely found in ap1-1 primary flowers, such organs are fairly common in secondary and higher order flowers (averaging 3.8 petals or petaloid organs per flower on 33 ap1-1 flowers counted). In contrast, the number of petaloid 
organs is severely reduced in ap 1- 1 ant- 6 double mutants (averaging 0.33 petals or petaloid organs per flower on 36 ap1-1 ant- 6 flowers counted). The double mutants also exhibit less internode elongation between primary and secondary flowers (Figure 1G).

Mutations in CLF result in curled leaves, early flowering, and flowers that show slight transformations of first whorl organs to carpels and of second whorl organs to stamens (Goodrich et al., 1997). In our growth conditions, the clf-2 phenotype was less severe, with fairly normal first whorl organs and small petals found in the second whorl (Figure $1 \mathrm{H})$. Cells on the adaxial surface of clf- 2 petals were similar to those on wild-type petals (Figure 4D). However, stomata and more irregularly shaped cells were present on the abaxial surface of clf- 2 petals (Figure $4 \mathrm{E}$ ). ant- 6 clf- 2 double mutants exhibit the curled leaves and early flowering of clf- 2 mutants and produce floral organs in whorls one, three, and four that resemble those in ant- 6 mutants (Figure $1 \mathrm{H}$ ). clf-2 ant- 6 second whorl organs vary in appearance, with some flowers exhibiting organs resembling very narrow petals and others having quite small, yellow organs (Figure 11). The adaxial surface of clf- 2 ant- 6 second whorl organs often resembles wild-type petals with conical-shaped cells (Figure $4 \mathrm{~F}$ ), but in some cases, flattened cells are also present (Figure 4G). The abaxial surface of clf- 2 ant- $6 \mathrm{sec}$ ond whorl organs appears similar to that of the single mutants (Figure $4 \mathrm{H}$ ).

\section{Reduction of Petals and Elimination of Some Gynoecium Tissues in lug-1 ant-6 Double Mutants}

Mutations in LUG result in a reduction in organ number and the production of narrow floral organs that somewhat resemble those of ant mutants (Figure 1] ; Liu and Meyerowitz, 1995). In addition, first whorl organs are sometimes staminoid or petaloid, and second whorl organs are often absent. Later flowers show more severe organ identity transformations than do earlier flowers. Defects in carpel fusion are also present in lug-1, with hornlike protrusions often present at the top of the carpel valves (Liu and Meyerowitz, 1995). Narrow sepals and stamens with two locules are found in the first and third whorls, respectively, of lug- 1 ant- 6 flowers (Figure 1K). lug- 1 ant- 6 flowers show a synergistic phenotype in the second and fourth whorls. Second whorl organs are usually missing, although very thin petals, petaloid filaments, or filaments are sometimes produced (Figures $1 \mathrm{~K}, 4 \mathrm{I}$, and $4 \mathrm{~J})$. The fourth whorl of lug- 1 ant- 6 plants consists of two carpels that are partially or completely unfused on one or both sides (Figure 1L). lug- 1 ant- 6 gynoecia show a marked decrease in stigmatic tissue and are completely missing all adaxial tissues, including ovules, placenta, and septa. The tops of lug- 1 ant- 6 gynoecia consist of pointed projections with epidermal cells characteristic of styles (Figure $4 K$ ). In a few cases, stigmatic papillar cells are present at the tip of these projections (Figure $4 \mathrm{~L}$ ).

\section{DISCUSSION}

\section{ANT Is a Redundant Repressor of AG in Second Whorl Cells}

Previous characterization of the phenotype of ap2-2 ant- 9 double mutants had suggested that ANT might play a role in AG repression (Elliott et al., 1996). This is now further supported by the phenotype of ap2- 1 ant- 6 flowers. Several differences exist between ANT and other cadastral regulators of $A G$ expression. Unlike mutations in AP2, LUG, CLF, and SAP, the ant single mutants show no obvious homeotic transformation of organ identity, indicating that the role of ANT in AG repression is entirely redundant with that of AP 2 . In addition, ANT appears to act as a second whorl-specific repressor of AG. Unlike AP2 and LUG, ANT is not involved in controlling the initiation of $A G$ expression. $A G$ expression is initiated in a normal pattern in stage 3 floral meristems of ap2-1 ant- 6 plants.

The enhancement of the ap2-1 phenotype when ant- 6 is heterozygous suggests that the amount of ANT activity is critical in flowers compromised for AP 2 activity and might indicate that ANT and AP2 interact directly or at least work in the same pathway. Previously, dominant interactions have been observed between lug and ap2 and between clf and ap2 (Liu and Meyerowitz, 1995; Goodrich et al., 1997). So far, all of the identified AG repressors have homology to either transcription factors (AP2, ANT, and SAP) (Elliott et al., 1996; Klucher et al., 1996; Byzova et al., 1999) or to a chromatin-associated protein (CLF) (Goodrich et al., 1997). One possibility is that some or all of these proteins form a complex involved in transcriptional repression of AG. Because of its severe mutant phenotype, AP2 is expected to be a critical subunit of such a complex. This complex might associate with chromatin-associated proteins to keep AG in a transcriptionally silent state in particular cells. Recently, AP2 has been shown to negatively regulate AG expression through several independent enhancer elements (Bomblies et al., 1999). The fact that multiple regulatory elements require AP2 activity for preventing AG expression in floral whorls one and two supports the idea that these factors might not work independently through different cis-acting elements but rather as a complex.

\section{ANT Acts to Promote Petal Cell Identity Independently of Its Role in AG Repression}

Although ant single mutants do not show homeotic alterations in organ identity, some second whorl abaxial epidermal cells lose petal identity. The presence of stomata and the morphology of the elongated cells suggest a transformation to anther identity, even though AG expression was not detected here. This suggests that ANT acts to repress other class $C$ genes involved in specifying stamen identity or that 

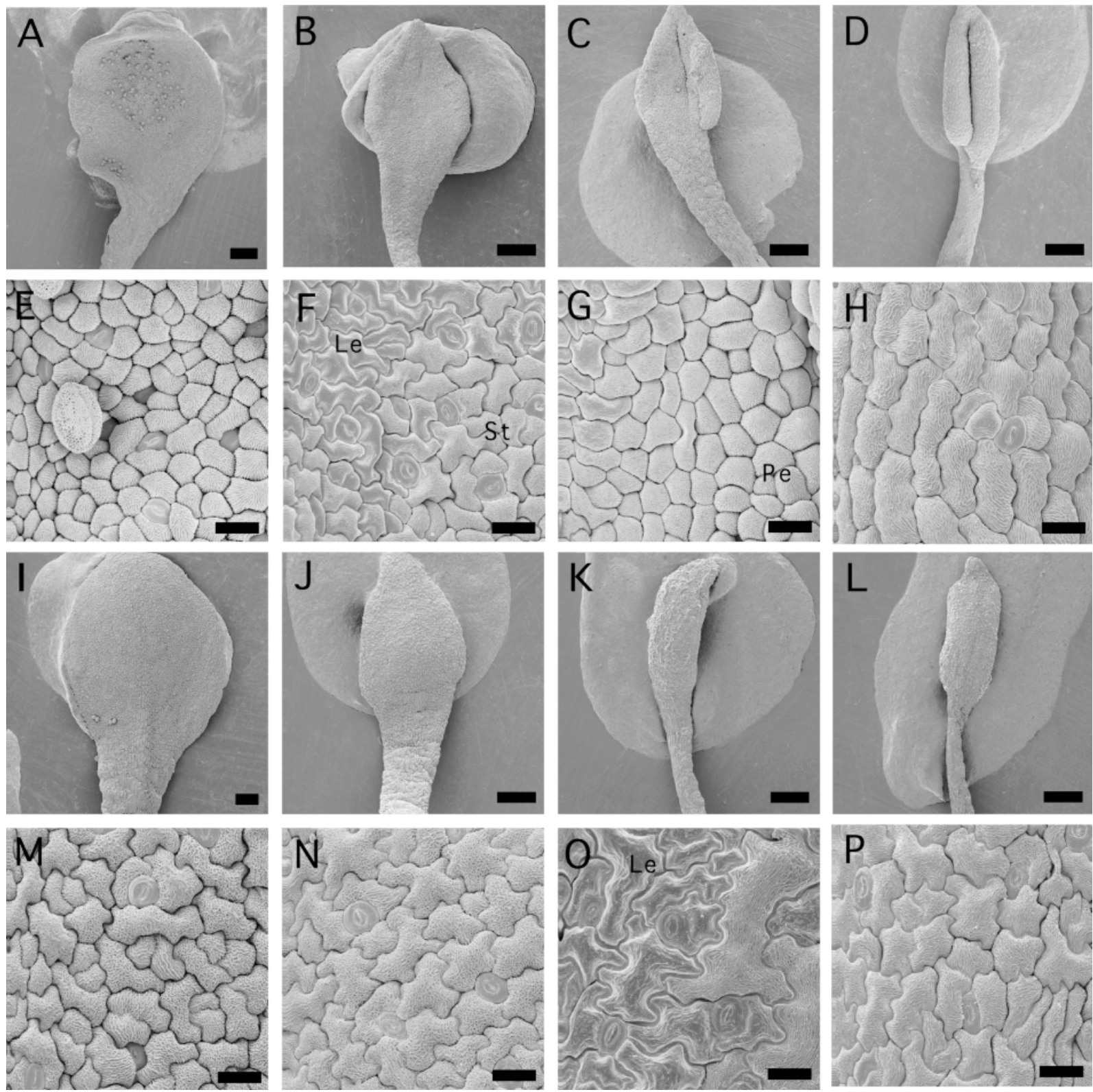

Figure 5. Scanning Electron Micrographs of ap2-1 and ap2-1 ant-6 Flowers.

(A) Low magnification of the adaxial surface of an ap2-1 second whorl organ.

(B) to (D) Low magnification of the adaxial surfaces of ap2-1 ant- 6 second whorl organs, showing various degrees of stamenlike features.

(E) High magnification of the adaxial surface of the ap2-1 second whorl organ shown in (A).

(F) to (H) High magnification of the adaxial surface of ap2-1 ant-6 second whorl organs shown in (B) to (D), respectively, with leaflike, petal-like, and stamenlike cells indicated.

(I) Low magnification of the abaxial surface of an ap2-1 second whorl organ.

(U) to (L) Low magnification of the abaxial surfaces of ap2-1 ant- 6 second whorl organs.

(M) High magnification of the abaxial surface of the ap2-1 second whorl organ shown in (I).

(N) to (P) High magnification of the abaxial surfaces of ap2-1 ant-6 second whorl organs shown in $(\mathbf{U})$ to (L), respectively.

Le, leaflike cells; Pe, petal-like cells; St, stamenlike cells. Bars in (A) to (D) and (I) to (L) $=100 \mu \mathrm{m}$; bars in (E) to (H) and (M) to (P) $=10 \mu \mathrm{m}$. 
ANT acts to promote petal identity in these cells. If ANT does act to repress other class $C$ genes, these genes must function independently of AG because ag- 3 ant- 6 petals exhibit a phenotype similar to that of ant- 6 petals.

That ANT might function as a class $A$ gene is supported by its role in $A G$ repression and by the phenotype of the ap1-1 ant- 6 double mutant, in which organs with any petal characteristics are almost completely eliminated. In this case, the ant second whorl abaxial phenotype could be explained by a decreased class A function with no corresponding expansion of class $C$ function, given that AP2 activity remains. $B$ function in the absence of $A$ and $C$ functions produces organs that are intermediate between petals and stamens and cells with intermediate morphologies (Bowman et al., 1991). If ANT does possess class A organ identity activity, this function is almost completely redundant with that of AP 1 and AP2, such that ant mutants show loss of petal identity in only one particular cell type. Unlike the other Arabidopsis A function genes, the roles of ANT in both organ identity specification and AG repression are restricted to a single whorl. Alternatively, ANT may not function as a class $A$ gene but rather as a specifier of a particular petal cell type. In this role, ANT would function downstream of the class $A$ and $B$ gene activities. Consistent with this proposed role, ANT is expressed at late stages in the petal abaxial epidermis (Elliott et al., 1996).

\section{Possible Roles of Class C Repressors in Evolution of Petals}

Most of the known AG repressors appear to be multifunctional genes that play several roles during flower development. LUG and ANT are involved in organ growth (Liu and Meyerowitz, 1995; Elliott et al., 1996; Klucher et al., 1996), AP2 and SAP have roles in specifying floral meristem identity (Bowman et al., 1993; Schultz and Haughn, 1993; Shannon and Meeks-Wagner, 1993; Byzova et al., 1999), and AP2, LUG, SAP, and ANT are all involved in ovule development (Modrusan et al., 1994; Elliott et al., 1996; Klucher et al., 1996; Baker et al., 1997; Roe et al., 1997; Schneitz et al., 1997; Byzova et al., 1999). Although these genes have slightly different roles with respect to the precise timing and spatial restriction of $A G$ expression, the presence of so many known regulators of $A G$ expression seems odd, considering that few regulators of class $B$ gene expression have been identified. Because ovules are evolutionarily older than flowers, these genes may have initially had roles in ovule development and were recruited for other roles in flower development at later times (Theissen et al., 2000).

Petals are hypothesized to have arisen independently several times from stamens (andropetals) or sterile bracts (bracteopetals) in different angiosperm lineages (Takhtajan, 1991). The evolution of andropetals from a duplicated whorl of stamens might have involved genes that repressed $C$ function in this region of the flower. Some of these genes later may have acquired functions in specifying petal organ identity. Because of the importance of petals in pollination, it might have been advantageous for these plants to maintain several repressors of $C$ function. It will be interesting to see whether AP2, ANT, LUG, and SAP-like genes are present in different angiosperms thought to have andropetals versus bracteopetals and whether these genes function in repression of class $\mathrm{C}$ genes and petal development in these different lineages.

\section{ANT Functions in Many Different Processes during Flower Development}

Consistent with its broad expression pattern in both vegetative and reproductive organs, ANT appears to function in several different developmental processes (Elliott et al., 1996; Klucher et al., 1996; Baker et al., 1997). On the basis of its single-mutant phenotype, ANT was shown to play a role in floral organ initiation and growth as well as integument initiation in ovules. Several additional roles have been uncovered through the analysis of double mutants. For example, ANT acts redundantly with HUELLENLOS (HLL) to specify ovule outgrowth along the proximal-distal axis (Schneitz et al., 1998). Here, we show that ANT acts redundantly with AP2 to repress AG in second whorl cells and in fact may function as a class $A$ gene with regard to specification of petal identity. Isolation of downstream target genes as well as of interacting proteins should help illuminate the manner in which this transcription factor works within these different developmental pathways.

\section{METHODS}

\section{Strain Constructions}

All double mutants were created by pollinating carpels from heterozygous ag- 3 and homozygous ap2-1, ap1-1, lug-1, and clf- 2 with pollen from ant- 6 homozygotes. ant- 6 is a putative null allele (Krizek, 1999). All ant- 6 double mutants could be identified by the presence of anthers with two locules. Because ANT is closely linked to AP2 and LUG, double mutants were identified in the $F_{3}$ of these crosses. Seeds from 30 individual $F_{1}$ plants from the ap2- 1 cross were planted as individual families. Of the $\sim 500$ total plants from these families, one showed a noticeably more severe phenotype than ap2-1. Genotyping of this plant by polymerase chain reaction (Krizek, 1999) showed it to be heterozygous for ant-6. Progeny from this plant segregated the ap 2- 1 ant- 6 double mutant.

\section{Scanning Electron Microscopy}

Samples for scanning electron microscopy were prepared and examined as previously described (Krizek, 1999). 


\section{In Situ Hybridization}

Nonradioactive in situ hybridizations were performed as previously described (Krizek, 1999). AG antisense probe was made by linearization of pCIT565 (Yanofsky et al., 1990) with HindIII and in vitro transcription with T7 RNA polymerase. ap2-1 and ap2-1 ant- 6 tissues of the same age were sectioned and put side by side on a slide for hybridization with the AG probe.

\section{ACKNOWLEDGMENTS}

We thank Charles Gasser for the ant- 4 seeds, David Taylor and Robert Raguso for interesting discussions, and J ohn Bowman for comments on the paper. This work was supported by U.S. Department of Energy Grant No. 98ER20312.

Received March 29, 2000; accepted J une 2, 2000.

\section{REFERENCES}

Baker, S.C., Robinson-Beers, K., Villanueva, J.M., Gaiser, J .C., and Gasser, C.S. (1997). Interactions among genes regulating ovule development in Arabidopsis thaliana. Genetics 145, 11091124

Bomblies, K., Dagenais, N., and Weigel, D. (1999). Redundant enhancers mediate transcriptional repression of AGAMOUS by APETALA2. Dev. Biol. 216, 260-264.

Bowman, J .L., Smyth, D.R., and Meyerowitz, E.M. (1989). Genes directing flower development in Arabidopsis. Plant Cell 1, 37-52.

Bowman, J .L., Smyth, D.R., and Meyerowitz, E.M. (1991). Genetic interactions among floral homeotic genes of Arabidopsis. Development 112, 1-20.

Bowman, J.L., Alvarez, J., Weigel, D., Meyerowitz, E.M., and Smyth, D.R. (1993). Control of flower development in Arabidopsis thaliana by APETALA1 and interacting genes. Development 119, 721-743.

Busch, M.A., Bomblies, K., and Weigel, D. (1999). Activation of a floral homeotic gene in Arabidopsis. Science 285, 585-587.

Byzova, M.V., Franken, J ., Aarts, M.G.M., de Almeida-Engler, J ., Engler, G., Mariana, C., Van Lookeren Campagne, M.M., and Angenent, G.C. (1999). Arabidopsis STERILE APETALA, a multifunctional gene regulating inflorescence, flower, and ovule development. Genes Dev. 13, 1002-1014.

Coen, E.S., and Meyerowitz, E.M. (1991). The war of the whorls: Genetic interactions controlling flower development. Nature 353, 31-37.

Drews, G.N., Bowman, J .L., and Meyerowitz, E.M. (1991). Negative regulation of the Arabidopsis homeotic gene AGAMOUS by the APETALA2 product. Cell 65, 991-1002.

Elliott, R.C., Betzner, A.S., Huttner, E., Oakes, M.P., Tucker, W.Q.J ., Gerentes, D., Perez, P., and Smyth, D.R. (1996). AINTEGUMENTA, an APETALA2-like gene of Arabidopsis with pleio- tropic roles in ovule development and floral organ growth. Plant Cell 8, 155-168.

Goodrich, J ., Puangsomlee, P., Martin, M., Long, D., Meyerowitz, E.M., and Coupland, G. (1997). A Polycomb-group gene regulates homeotic gene expression in Arabidopsis. Nature 386, 44-51.

Irish, V.F., and Sussex, I.M. (1990). Function of the APETALA-1 gene during Arabidopsis floral development. Plant Cell 2, 741-753.

Klucher, K.M., Chow, H., Reiser, L., and Fischer, R.L. (1996). The AINTEGUMENTA gene of Arabidopsis required for ovule and female gametophyte development is related to the floral homeotic gene APETALA2. Plant Cell 8, 137-153.

Krizek, B.A. (1999). Ectopic expression of AINTEGUMENTA in Arabidopsis plants results in increased growth of floral organs. Dev. Genet. 25, 224-236.

Liu, Z., and Meyerowitz, E.M. (1995). LEUNIG regulates AGAMOUS expression in Arabidopsis flowers. Development 121, 975-991.

Meyerowitz, E.M., Bowman, J .L., Brockman, L.L., Drews, G.N., J ack, T.J ., Sieburth, L., and Weigel, D. (1991). A genetic and molecular model for flower development in Arabidopsis thaliana. Dev. Suppl. 1, 157-167.

Modrusan, Z., Reiser, L., Feldmann, K.A., Fischer, R.L., and Haughn, G.W. (1994). Homeotic transformation of ovules into carpel-like structures in Arabidopsis. Plant Cell 6, 333-349.

Parcy, F., Nilsson, O., Busch, M.A., Lee, I., and Weigel, D. (1998). A genetic framework for floral patterning. Nature 395, 561-566.

Roe, J.L., Nemhauser, J.L., and Zambryski, P.C. (1997). TOUSLED participates in apical tissue formation during gynoecium development in Arabidopsis. Plant Cell 9, 335-353.

Sanders, P.M., Bui, A.Q., Weterings, K., McIntire, K.N., Hsu, Y.-C., Lee, P.Y., Truong, M.T., Beals, T.P., and Goldberg, R.B. (1999). Anther developmental defects in Arabidopsis thaliana male-sterile mutants. Sex. Plant Reprod. 11, 297-322.

Schneitz, K., Hulskamp, M., Kopczak, S.D., and Pruitt, R.E. (1997). Dissection of sexual organ ontogenesis: A genetic analysis of ovule development in Arabidopsis thaliana. Development 124, 1367-1376.

Schneitz, K., Baker, S.C., Gasser, C.S., and Redweik, A. (1998). Pattern formation and growth during floral organogenesis: HUELLENLOSS and AINTEGUMENTA are required for the formation of the proximal region of the ovule primordia in Arabidopsis thaliana. Development 125, 2555-2563.

Schultz, E.A., and Haughn, G.W. (1993). Genetic analysis of the floral initiation process (FLIP) in Arabidopsis. Development 119, 745-765.

Shannon, S., and Meeks-Wagner, D. (1993). Genetic interactions that regulate inflorescence development in Arabidopsis. Plant Cell 5, 639-655.

Takhtajan, A. (1991). Evolutionary Trends in Flowering Plants. (New York: Columbia University Press).

Theissen, G., Becker, A., Di Rosa, A., Kanno, A., Kim, J .T., Munster, T., Winter, K.-U., and Saedler, H. (2000). A short history of MADS-box genes in plants. Plant Mol. Biol. 42, 115-149.

Yanofsky, M.F., Ma, H., Bowman, J .L., Drews, G.N., Feldman, K., and Meyerowitz, E.M. (1990). The protein encoded by the Arabidopsis homeotic gene AGAMOUS resembles transcription factors. Nature 346, 35-39. 